Received 00th January 20xx, Accepted 00th January 20xx DOI: $10.1039 / x 0 x \times 00000 x$

\title{
Asymmetric Diastereodivergent Michael Addition of 2- Chloromalonate Esters to Conjugated Imines Enabled by Catalyst Metal Change ${ }^{\dagger}$
}

\begin{abstract}
Miguel Espinosa, ${ }^{a}$ Gonzalo Blay, ${ }^{* a}$ Luz Cardona, ${ }^{a}$ Pedro Merino, ${ }^{* b}$ and José R. Pedro*a
Despite recent progress in asymmetric diastereodivergent reactions leading to products bearing two stereogenic centers, little research has been devoted to processes were a stereogenic center and a double bond are formed. Here, we report the asymmetric diastereodivergent Michael addition of 2 -chloromalonate esters to $N$-tosyl $\beta$, $\gamma$-unsaturated $\alpha$-ketimino esters to give chiral $\alpha, \beta$-dehydro- $\alpha$-aminoesters bearing either a $Z$ or $E$ enamine moiety, using pyBOX-metal complexes. Diastereodivergency is achieved by simply changing the metal ion from a trivalent $\mathrm{La}$ (III) to a divalent $\mathrm{Ca}$ (II) ion, providing the $Z$ or $E$ enamines. Computational studies reveal the crucial role of London interactions between the aromatic residues on the imine and the pyBOX ligand, which are conditioned by the different coordination modes of $\mathrm{La}(\mathrm{III}) \mathrm{and} \mathrm{Ca}(\mathrm{II})$, in the change of selectivity depending on the used metal.
\end{abstract}

\section{Introduction}

Stereoselective synthesis (diastereo- and enantioselective) is an important goal for organic chemists as both the absolute and relative configurations have an impact on the properties of a compound, for example, in terms of its physiological or pharmacological activity. ${ }^{1}$ Over the past decades, asymmetric catalysis has proven to be a powerful tool to synthesize enantioenriched molecules. In general, complementary access to one or the opposite enantiomer of a molecule (enantiodivergency) has been granted by the choice of which enantiomeric (or pseudoenantiomeric) form of the catalyst is employed. ${ }^{2}$ However, in many cases these reactions led to an inherently preferred diastereomer, while the other cannot be accessed due to the diastereomeric bias of the substrate. Therefore, the development of diastereodivergent methods that allow the synthesis of one diastereomer in one enantiomeric form at will, in a single step starting from the same set of reactants is of great importance in asymmetric catalysis. ${ }^{3}$ Representative procedures include the adjustment of the reaction parameters (solvents, additives, temperature), the use of distinct catalysts or ligands, or two chiral catalystsbased dual catalysis, among others. ${ }^{4}$ It should be noticed, however, that most of the efforts on asymmetric diastereodivergent synthesis have been focused on reactions

\footnotetext{
a. Departament de Química Orgànica, Facultat de Química, Universitat de València, C/ Dr. Moliner 50, 46100-Burjassot, Spain.

b. Instituto de Biocomputación y Física de Sistemas Complejos (BIFI), Universidad de Zaragoza, 50009-Zaragoza, Spain.

† Footnotes relating to the title and/or authors should appear here.

Electronic Supplementary Information (ESI) available: Experimental procedures, characterization data, NMR spectra, HPLC traces, computational methods, energy values, energy profiles, cartesian coordinates.See DOI: 10.1039/x0xx00000x
}

were two stereogenic centers are generated in the target molecule (Scheme 1a), ${ }^{5}$ while other situations have been less explored.

a) two sterogenic centers (many asymmetric diastereodivergent examples)

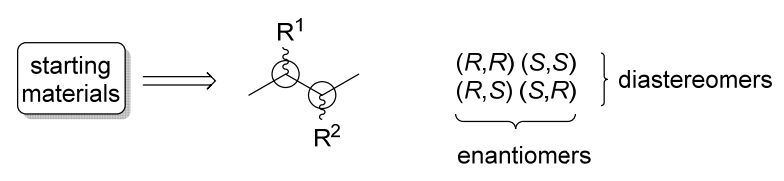

b) one sterogenic center and one double bond (few asymmetric diastereodivergent examples)

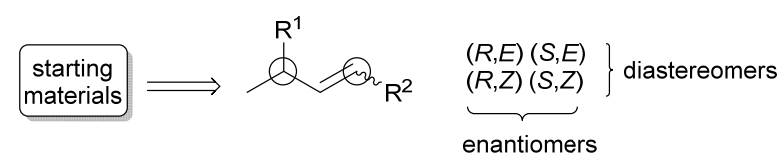

c) asymmetric diastereodivergent Michael addition to conjugated imines (this work).

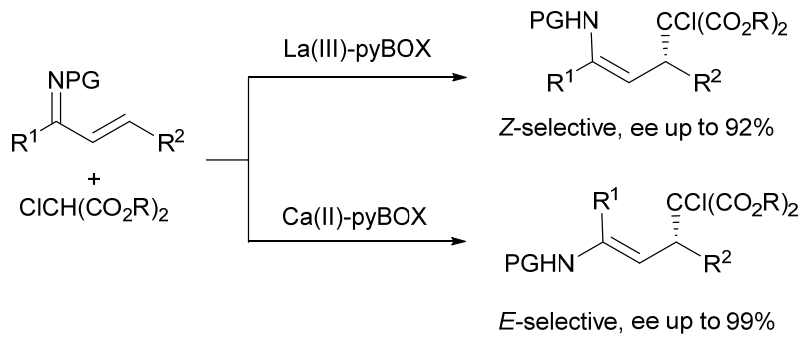

Scheme 1. Reactions leading to chiral diastereomeric products, potentially amenable to asymmetric diastereodivergent synthesis.

For instance, reactions were a stereogenic center and a stereogenic double bond are formed simultaneously can lead also to four chiral stereoisomers differing on the configuration of the stereogenic center and/or the geometry of the double 
bond (Scheme 1b). In such scenario the catalyst has to exert two distinct stereodifferentiation effects: By one hand it has to control the stereochemistry of a three-dimensional stereogenic center, responsible of the chirality, and on the other hand it has to control the geometry of a planar double bond, responsible for the formation of diastereomers (Scheme 1b).

Conjugate nucleophilic addition reactions to $\alpha, \beta$-unsaturated imines are representative of this group of reactions (Scheme 1c), where a chiral carbon and an enamine double bond are formed (four chiral stereoisomers being possible). A number of enantioselective conjugate additions to these substrates have been reported in the literature, some of them diastereoselective, but none of them have been carried out in an asymmetric diastereodivergent manner. For instance, the groups of Carretero ${ }^{6}$ and Palacios $^{7}$ have reported the enantioselective copper-catalyzed conjugate addition of dialkylzinc reagents to $\alpha, \beta$-unsaturated imines to give the $Z$ enamines with good diastereo- and enantioselectivity. Lee and Kim have reported a diastereo- and enantioselective conjugate addition of arylboronic acids to $\beta, \gamma$-unsaturated $\alpha$-ketimino esters catalyzed by rhodium $(I),{ }^{8}$ and the group of Leung has achieved the highly enantioselective hydrophosphination of $\alpha, \beta$-unsaturated ketimines catalyzed by a chiral palladacycle, ${ }^{9}$ both reactions yielding the $Z$ enamines as the major isomers. Recently, Xu reported a diastereodivergent protosilylation of $\alpha, \beta$-unsaturated ketimines to give either the $E$ or $Z$ functionalized chiral allylsilanes. However, only the $E$-isomer was obtained with good enantiomeric excesses, while the $Z$ isomer only could be obtained in racemic form. ${ }^{10}$

As a part of our research, we have reported the nondiastereodivergent enantioselective Michael reaction with $\mathrm{N}$ sulfonylimines derived from chalcones ${ }^{11}$ as well as the diastereodivergent but non-enantioselective MukaiyamaMichael addition of silyl enol ethers to $N$-tosylimines derived from $\beta, \gamma$-unsaturated $\alpha$-keto esters to give racemic $\alpha, \beta$ dehydro- $\alpha$-aminoesters. ${ }^{12} \alpha, \beta$-Dehydroaminoacid derivatives are non-proteinogenic amino acids that are often found as structural subunits in natural products of different origin, and they also are intermediates in the synthesis of natural and unnatural $\alpha$-amino acids. ${ }^{13}$ Some of them have shown antibiotic and other intriguing biological activities, which depend not only on their absolute stereochemistry but also on the $E / Z$ configuration of the double bond of the dehydroaminoacid moiety. ${ }^{14}$ Herein we report the development of catalytic methods to achieve the enantioselective synthesis of chiral $\alpha, \beta$-dehydroaminoesters with a defined $E$ or $Z$ geometry at the enamine double bond, with high enantiomeric excesses, via the asymmetric diastereodivergent Michael addition of malonic esters to $\beta, \gamma$ unsaturated $\alpha$-ketimino esters. To the best of our knowledge this is the only example of conjugate addition to unsaturated imines which is diastereodivergent and enantioselective for both diastereomers.

\section{Results and discussion}

As part of our preliminary work on this subject, ${ }^{15}$ we performed the reaction of diethyl malonate 1 to $N$-tosyl $\beta, \gamma$ unsaturated $\alpha$-ketimino esters 2 . We found that the complex of $\mathrm{La}(\mathrm{OTf})_{3}$ and the diphenyl-pyBOX ligand pyBOX1 promoted the enantioselective conjugate addition providing the chiral $\alpha, \beta$-dehydroaminoesters $\mathbf{3}$ with excellent yields, good diastereoselectivity favoring the $Z$ enamines and good to high enantiomeric excesses. The reaction could be applied to imines having a substituted aromatic ring or a heterocycle attached to the double bond. Some representative examples are shown in Table 1.

Table 1. Enantioselective addition of diethyl malonate (1) to $N$-tosyl $\beta, \gamma$-unsaturated $\alpha$ ketimino esters $\mathbf{2}$ catalyzed by La(OTf) ${ }_{3}$-pyBOX1. ${ }^{a}$

$\begin{array}{cccccccccc} & & & & & & & & \\ 1\end{array}$

a Reaction conditions: 1 (0.6 mmol), $2(0.25 \mathrm{mmol})$, pyBOX1 $(0.025 \mathrm{mmol})$, $\mathrm{La}(\mathrm{OTf})_{3}(0.025 \mathrm{mmol}), 4 \AA \mathrm{MS}(110 \mathrm{mg})$, solvent $(2.2 \mathrm{~mL})$, rt. Results taken from ref. 14. ${ }^{b}$ Yield of isolated product. ${ }^{\mathrm{c}}$ Determined by ${ }^{1} \mathrm{H}$ NMR. ${ }^{\mathrm{d}}$ Only for the major $Z$ diastereomer. Determined by HPLC with chiral stationary phases.

To extend the scope and potential application of the method, we undertook the study of the reaction of dialkyl 2chloromalonates and ketimino esters, which provides highly functionalized chloro-enamino esters (Scheme 2). ${ }^{\ddagger}$ The introduction of highly functionalized fragments into an organic molecule is of paramount importance in organic synthesis since this allows increasing the possibilities of further functional or structural modifications in later stages of the synthetic sequence. 


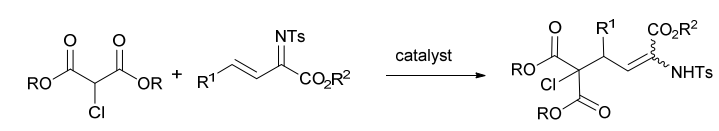<smiles>[R]c1nc(-c2cccc(C3=NC([R])C(C(F)F)O3)n2)oc1P</smiles>
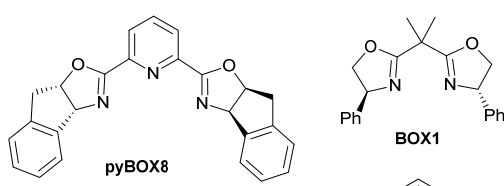

pyBOX1, $R=P h, R^{\prime}=H$ pyBOX2, $R=\mathbb{P r}, \mathrm{R}^{\prime}=\mathrm{H}$ pyBOX3, $R=t B u, R^{\prime}=H$ pyBOX4, $R=\mathbb{P r C H}_{2}, \mathrm{R}^{\prime}=\mathrm{H}$
pyBOX5, $\mathrm{R}=\mathrm{BnCH}_{2}, \mathrm{R}^{\prime}=\mathrm{H}$ pyBOX6, $\mathrm{R}=1$-naphthyl- $\mathrm{CH}_{2}, \mathrm{R}^{\prime}=$ pyBOX7, $R=M e, R^{\prime}=P h$

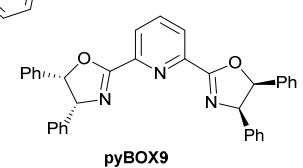

Scheme 2. Conjugate addition of 2-chloromalonate esters to $\mathrm{N}$-tosyl imines derived from $\beta, \gamma$-unsaturated $\alpha$-keto esters, and ligands used in this study.

\section{La(III)-Catalyzed reaction. Synthesis of Z-Enamines}

The conditions previously developed for the addition of diethyl malonate with the $\mathrm{La}(\mathrm{OTf})_{3}$-pyBOX1 catalyst were initially applied to the reaction between diethyl 2-chloromalonate $(4)^{\ddagger}$ and imine $\mathbf{2 a}$, which led to the Z-enamine $\mathbf{5 a}$ with high $\mathrm{dr}$ (3:97) and $82 \%$ ee (Table 2, entry 1 ).

Table 2. Enantioselective addition of diethyl 2-chloromalonate (4) to imine 2a catalyzed by pyBOX-La(OTf) complexes. $^{\text {a }}$

$$
\underbrace{\mathrm{OaEt}}_{2 \mathrm{Cl}}
$$$$
(E: Z)^{\mathrm{c}} \quad \text { ee }(\%)^{\mathrm{d}}
$$

\begin{tabular}{cccccccc} 
entry & ligand & $t(\mathrm{~h})$ & $T\left({ }^{\circ} \mathrm{C}\right)$ & yield $(\%)^{\mathrm{b}}$ & $(E: Z)^{\mathrm{c}}$ & ee $(\%)^{\mathrm{d}}$ & \\
\hline $1^{\mathrm{e}}$ & pyBOX1 & 16 & $\mathrm{rt}$ & 97 & $3: 97$ & 82 & $R, Z$
\end{tabular}

$2 \begin{array}{llllllll}2 & \text { pyBOX1 } & 14 & \mathrm{rt} & 92 & 3: 97 & 82 & R, Z\end{array}$

$\begin{array}{lllllllll}3 & \text { pyBOX2 } & 19 & \mathrm{rt} & 89 & 4: 96 & 22 & R, Z\end{array}$

$\begin{array}{llllllll}4 & \text { рувОх3 } & 16 & \mathrm{rt} & 88 & 9: 91 & 16 & R, Z\end{array}$

$\begin{array}{llllllll}5 & \text { pyBOX4 } & 39 & \mathrm{rt} & 90 & 7: 93 & 3 & R, Z\end{array}$

$\begin{array}{llllllll}6 & \text { pyBOX5 } & 40 & \mathrm{rt} & 87 & 7: 93 & 44 & R, Z\end{array}$

$\begin{array}{llllllll}7 & \text { pyвох6 } & 40 & \mathrm{rt} & 91 & 8: 92 & 41 & R, Z\end{array}$

$\begin{array}{lllllllll}8 & \text { pyBOX7 } & 16 & \mathrm{rt} & 92 & 7: 93 & 46 & R, Z\end{array}$

$\begin{array}{llllllll}9 & \text { pyBOX8 } & 43 & \mathrm{rt} & 92 & 10: 90 & 13 & \mathrm{~S}, \mathrm{Z}\end{array}$

$\begin{array}{llllllll}10 & \text { pyBOX9 } & 16 & \mathrm{rt} & 93 & 2: 98 & 82 & \mathrm{~S}, \mathrm{Z}\end{array}$

$\begin{array}{llllllll}11 & \text { pyBOX1 } & 40 & 0 & 89 & 5: 95 & 82 & R, Z\end{array}$

$\begin{array}{llllllll}12 & \text { pyBOX9 } & 22 & 0 & 93 & 3: 97 & 83 & S, Z\end{array}$

$\begin{array}{llllllll}13 & \text { pyBOX9 } & 40 & -10 & 83 & 8: 92 & 86 & S, Z\end{array}$

$\begin{array}{llllllll}14^{\mathrm{e}, \mathrm{f}} & \text { BOX1 } & 16 & \mathrm{rt} & 86 & 90: 10 & 77 & S, E\end{array}$

a Reaction conditions: 4 (0.187 mmol), 2a (0.125 mmol), pyBOX $(0.0125 \mathrm{mmol})$, La(OTf)3 (0.0125 mmol), $4 \AA \mathrm{MS}(110 \mathrm{mg}), \mathrm{CH}_{2} \mathrm{Cl}_{2}(1.1 \mathrm{~mL}) .{ }^{\mathrm{b}}$ Yield of isolated product. ${ }^{c}$ Determined by ${ }^{1} \mathrm{H}$ NMR. d Only for the major diastereomer. Determined by HPLC analysis with chiral stationary phases. ${ }^{e}$ Reaction carried out with $0.3 \mathrm{mmol}$ of $4,0.125 \mathrm{mmol}$ of $2 \mathrm{a}$. ${ }^{\mathrm{f}}$ Reaction carried out with $\mathrm{Cu}(\mathrm{OTf})_{2}$ instead of $\mathrm{La}(\mathrm{OTf})_{3}$.

It was also found that the amount of diethyl 2-chloromalonate could be reduced to 1.5 equivalents without any noticeable effect (Table 2, entry 2). Different pyBOX ligands were then tested. All of them led to poorer results than pyBox1 (Table 2, entries 3-9) except pyBOX9, which performed similarly (Table 2 , entry 10). A decrease in the reaction temperature in the presence of pyBOx1 or pyBOx9 had little impact on the enantioselectivity, although the pyBOX9 complex seemed to be slightly more active (Table 2, entries 11 and 12). Decreasing the temperature to $-10{ }^{\circ} \mathrm{C}$ improved the ee up to $86 \%$ (Table 2, entry 13).

PyBOX1 complexes with other trivalent metal triflates such as $\mathrm{Yb}(\mathrm{OTf})_{3}, \mathrm{Sc}(\mathrm{OTf})_{3}$ or $\operatorname{In}(\mathrm{OTf})_{3}$ were also assessed but proved to be inactive and did not yield enamine $5 \mathbf{a}$. Furthermore, while performing this study, we also tested the $\mathrm{Cu}(\mathrm{OTf})_{2}$-BOX1 complex as catalyst, which allowed obtaining compound $\mathbf{5 a}$ in $86 \%$ yield after $16 \mathrm{~h}$. Quite surprisingly, the $E$ - instead of the $Z$ enamine was obtained as the major diastereomer with this catalyst, although with moderate $73 \%$ ee (Table 2 , entry 14 ). With the optimized conditions in hand (Table 2, entry 13), we proceeded to study the scope of this reaction with a number of unsaturated imines $\mathbf{2}$ (Table 3 ).

Table 3. Enantioselective addition of dialkyl 2-chloromalonates to unsaturated imines 2

\begin{tabular}{|c|c|c|c|c|c|c|c|c|c|c|}
\hline entry & & $\mathrm{R}$ & & $\mathrm{R}^{1}$ & $\mathrm{R}^{2}$ & $t(\mathrm{~h})$ & & yield $(\%)^{b}$ & $(E: Z)^{\mathrm{c}}$ & ee $(\%)^{d}$ \\
\hline 1 & 4 & Et & $2 a$ & $\mathrm{Ph}$ & Et & 40 & $5 a$ & 83 & $8: 92$ & 86 \\
\hline 2 & 4 & Et & $2 b$ & 4- $\mathrm{MeC}_{6} \mathrm{H}_{4}$ & Et & 94 & $5 b$ & 89 & $5: 95$ & 86 \\
\hline 3 & 4 & Et & 2c & $4-\mathrm{ClC}_{6} \mathrm{H}_{4}$ & Et & 91 & $5 c$ & 89 & $6: 94$ & 86 \\
\hline 4 & 4 & Et & $2 d$ & $4-\mathrm{NO}_{2} \mathrm{C}_{6} \mathrm{H}_{4}$ & Et & 42 & $5 d$ & 93 & $2: 98$ & 87 \\
\hline 5 & 4 & Et & $2 e$ & 4- $\mathrm{MeOC}_{6} \mathrm{H}_{4}$ & Et & 90 & $5 e$ & 99 & $4: 96$ & 86 \\
\hline 6 & 4 & Et & $2 f$ & $3-\mathrm{ClC}_{6} \mathrm{H}_{4}$ & Et & 91 & $5 f$ & 91 & $11: 89$ & 82 \\
\hline 7 & 4 & Et & $2 g$ & $3-\mathrm{NO}_{2} \mathrm{C}_{6} \mathrm{H}_{4}$ & Et & 40 & $5 g$ & 99 & $4: 96$ & 87 \\
\hline 8 & 4 & Et & $2 \mathrm{~h}$ & 3- $\mathrm{MeOC}_{6} \mathrm{H}_{4}$ & Et & 67 & $5 h$ & 99 & $24: 76$ & 85 \\
\hline 9 & 4 & Et & $2 \mathbf{i}$ & $2-\mathrm{ClC}_{6} \mathrm{H}_{4}$ & Et & 45 & $5 i$ & 91 & $3: 97$ & 88 \\
\hline 10 & 4 & Et & $2 j$ & $2-\mathrm{NO}_{2} \mathrm{C}_{6} \mathrm{H}_{4}$ & Et & 69 & $5 j$ & 99 & $6: 94$ & 88 \\
\hline 11 & 4 & Et & $2 k$ & $2-\mathrm{MeOC}_{6} \mathrm{H}_{4}$ & Et & 63 & $5 k$ & 99 & 1:99 & 87 \\
\hline 12 & 4 & Et & 21 & 2-thiophenyl & Et & 40 & 51 & 94 & $1: 99$ & 84 \\
\hline 13 & 4 & Et & $2 m$ & $\mathrm{Ph}$ & $\mathrm{Me}$ & 43 & $5 \mathrm{~m}$ & 91 & $8: 92$ & 83 \\
\hline 14 & 4 & Et & $2 n$ & $\mathrm{Ph}$ & $i \mathrm{Pr}$ & 43 & $5 n$ & 84 & $2: 98$ & 92 \\
\hline 15 & 4 & Et & 20 & $\mathrm{Me}$ & Et & 48 & $-{ }^{e}$ & - & - & \\
\hline 16 & 6 & $\mathrm{Me}$ & $2 a$ & $\mathrm{Ph}$ & Et & 15 & $7 a$ & 82 & 5:95 & 84 \\
\hline
\end{tabular}
catalyzed by La(OTf) ${ }_{3}$-pyBOX9.

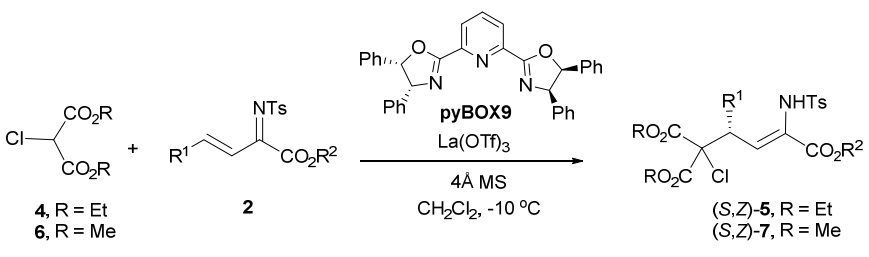

a Reaction conditions: 4 or $6(0.187 \mathrm{mmol}), 2$ (0.125 mmol), pyBOX9 (0.0125 $\mathrm{mmol}), \mathrm{La}(\mathrm{OTf})_{3}(0.0125 \mathrm{mmol}), 4 \AA \mathrm{MS}(110 \mathrm{mg}), \mathrm{CH}_{2} \mathrm{Cl}_{2}(1.1 \mathrm{~mL}),-10{ }^{\circ} \mathrm{C}$. ${ }^{\mathrm{b}}$ Yield of isolated product. ${ }^{\mathrm{c}}$ Determined by ${ }^{1} \mathrm{H}$ NMR. ${ }^{d}$ Determined by HPLC with chiral

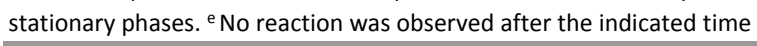


The addition of diethyl 2-chloromalonate (4) could be successfully achieved with a number of unsaturated imines having a substituted aromatic ring attached to the double bond ( $\gamma$-position). Excellent yields were obtained in all the cases regardless the position and electronic nature of the substituent on the aromatic ring (Table 3, entries 1-11). The $Z$ isomer was obtained as the major one in all the cases with very high diastereoselectivity, which was a little bit lower with imines substituted with a 3-chloro- or 3-methoxyphenyl group (Table 3, entries 6 and 8). Enantiomeric excesses above $80 \%$ were obtained for the major diastereomer in all the cases. It is worth remarking that the presence of nitro groups did not lessen the stereoselectivity. The imine also allowed a 2thiophenyl group attached to the double bond (Table 3, entry 12). A bulkier $i \operatorname{Pr}$ group at the ester moiety produced a rise in the enantiomeric excess up to $92 \%$ ee (Table 3 , entry 14 ), while the methyl ester performed similarly to the ethyl derivative (Table 3 , entry 13 vs entry 1 ). Imine 20 bearing a methyl group attached to the double bond was also tested as reaction substrate (Table 3 , entry 15 ). Unfortunately no Michael addition was observed after 48 hours, most probably due to tautomerization of imine 20 to its dienamine form. Finally, dimethyl 2-chloromalonate (6) was also tested giving similar results as diethyl 2-chloromalonate (Table 3, entry 16 vs entry 1$)$.

\section{$\mathrm{Ca}$ (II)-Catalyzed reaction. Synthesis of $E$-Enamines}

As it has been previously mentioned, the use of the $\mathrm{Cu}(\mathrm{OTf})_{2^{-}}$ BOX1 instead of La(OTf) - $_{3}$-pyBOX9 in the reaction of $\mathbf{4}$ and $\mathbf{2 a}$ produced a shift of diastereoselectivity towards the $E$-enamine (Table 2, entry 14). Although (E)-5aa was obtained only with fair enantioselectivity, this change of selectivity prompted us to check other catalysts based on divalent metals (Table 4).

Table 4. Enantioselective addition of diethyl 2-chloromalonate (4) to imine 2a catalyzed by complexes of divalent metal triflates. ${ }^{\mathrm{a}}$

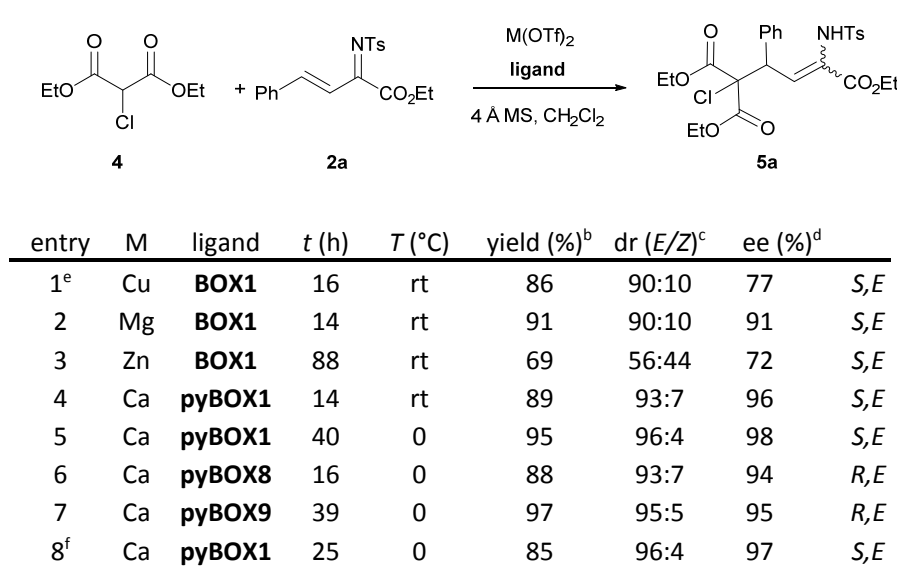

a Reaction conditions: 1a $(0.187 \mathrm{mmol}), 2 \mathrm{a}(0.125 \mathrm{mmol})$, ligand $(0.0125 \mathrm{mmol})$, $\mathrm{M}(\mathrm{OTf})_{2}(0.0125 \mathrm{mmol}), 4 \AA \mathrm{MS}(110 \mathrm{mg}), \mathrm{CH}_{2} \mathrm{Cl}_{2}(1.1 \mathrm{~mL}){ }^{\mathrm{b}}$ Yield of isolated product. ${ }^{\mathrm{c}}$ Determined by ${ }^{1} \mathrm{H}$ NMR. ${ }^{\mathrm{d}}$ Only for the major diastereomer. Determined by HPLC analysis with chiral stationary phases. ${ }^{e}$ Reaction carried out with 0.3 mmol of $1 \mathbf{a} / 0.125 \mathrm{mmol}$ of $2 \mathrm{a}^{\mathrm{f}}$ Reaction carried out with $0.00625 \mathrm{mmol}$ of pyBOX1-Ca(OTf) 2 .
The BOX1 complexes of $\mathrm{Cu}(\mathrm{II}), \mathrm{Mg}(\mathrm{II})$ and $\mathrm{Zn}(\mathrm{II})$ triflates, and the $\mathrm{Ca}(\mathrm{OTf})_{2}$-pyBOX1 were tested in the reaction of $\mathbf{4}$ and $\mathbf{2 a}$ (Table 4, entries 1-4). In all the cases the reaction showed $E$ selectivity, the $\mathrm{Ca}(\mathrm{OTf})_{2}$-pyBOX1 catalyst giving the best result (Table 4, entry 4). Decreasing the temperature to $0{ }^{\circ} \mathrm{C}$ allowed further improvement of the stereoselectivity (Table 4, entry 5). The Ca(II) complexes with pyвоx8 and pyBox9 (Table 4, entries 6 and 7) gave similar results to pyBOX1. Finally, it should be remarked that the catalyst load could be reduced to $5 \mathrm{~mol} \%$ without a noticeable impact on the result (Table 4, entry 8). On the view of these results, further optimization was not considered necessary.

Table 5. Enantioselective addition of dialkyl 2-chloromalonates to unsaturated imines 2 catalyzed by $\mathrm{Ca}(\mathrm{OTf})_{2}$-pyBOX1.

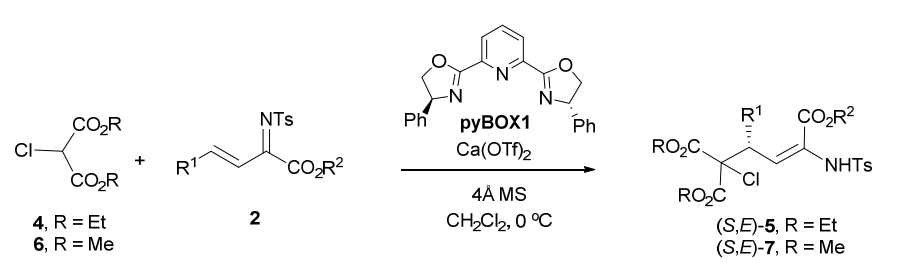

\begin{tabular}{|c|c|c|c|c|c|c|c|c|c|}
\hline entry & & $\mathrm{R}$ & $\mathrm{R}^{1}$ & $\mathrm{R}^{2}$ & $t(\mathrm{~h})$ & & yield $(\%)^{b}$ & $(E / Z)^{c}$ & ee $(\%)^{d}$ \\
\hline 1 & 4 & Et & 2a Ph & $\mathrm{Et}$ & 25 & $5 a$ & 85 & $96: 4$ & 97 \\
\hline 2 & 4 & Et & 2b $4-\mathrm{MeC}_{6} \mathrm{H}_{4}$ & Et & 38 & $5 b$ & 94 & $96: 4$ & 98 \\
\hline 3 & 4 & Et & 2c $4-\mathrm{ClC}_{6} \mathrm{H}_{4}$ & Et & 39 & $5 c$ & 95 & $95: 5$ & 98 \\
\hline 4 & 4 & Et & 2d $4-\mathrm{NO}_{2} \mathrm{C}_{6} \mathrm{H}_{4}$ & Et & 23 & $5 d$ & 99 & $92: 8$ & 98 \\
\hline 5 & 4 & Et & 2e $4-\mathrm{MeOC}_{6} \mathrm{H}_{4}$ & Et & 38 & $5 e$ & 99 & $95: 5$ & 98 \\
\hline 6 & 4 & Et & 2f $3-\mathrm{ClC}_{6} \mathrm{H}_{4}$ & Et & 39 & $5 f$ & 91 & $95: 5$ & 98 \\
\hline 7 & 4 & Et & $2 \mathrm{~g} \mathrm{3}-\mathrm{NO}_{2} \mathrm{C}_{6} \mathrm{H}_{4}$ & Et & 40 & $5 g$ & 99 & $93: 7$ & 93 \\
\hline 8 & 4 & Et & 2h 3- $\mathrm{MeOC}_{6} \mathrm{H}_{4}$ & Et & 44 & $5 \mathrm{~h}$ & 98 & $96: 4$ & 96 \\
\hline 9 & 4 & Et & $2 \mathrm{i} \quad 2-\mathrm{ClC}_{6} \mathrm{H}_{4}$ & Et & 93 & $5 i$ & 95 & $95: 5$ & 98 \\
\hline 10 & 4 & Et & 2j $2-\mathrm{NO}_{2} \mathrm{C}_{6} \mathrm{H}_{4}$ & Et & 44 & $5 j$ & 98 & $97: 3$ & 99 \\
\hline 11 & 4 & Et & 2k $2-\mathrm{MeOC}_{6} \mathrm{H}_{4}$ & Et & 63 & $5 k$ & 99 & $95: 5$ & 95 \\
\hline 12 & 4 & Et & 2l 2-thiophenyl & Et & 23 & 51 & 99 & $97: 3$ & 97 \\
\hline 13 & 4 & Et & $2 \mathrm{mPh}$ & $\mathrm{Me}$ & 42 & $5 m$ & 91 & $96: 4$ & 98 \\
\hline 14 & 4 & Et & 2n Ph & $i \mathrm{Pr}$ & 66 & $5 n$ & 84 & $94: 6$ & 98 \\
\hline 15 & 4 & Et & $20 \mathrm{Me}$ & Et & 48 & 50 & $-\mathrm{e}$ & - & \\
\hline 16 & 6 & $\mathrm{Me}$ & 2a Ph & Et & 15 & $7 a$ & 92 & $92: 8$ & 98 \\
\hline 17 & 1 & Et & 2a Ph & Et & 100 & $3 a$ & $-e$ & & \\
\hline
\end{tabular}

a 4 or $6(0.187 \mathrm{mmol}), 2(0.125 \mathrm{mmol})$, pyBOX1 (0.00625 mmol), $\mathrm{Ca}(\mathrm{OTf})_{2}(0.0125$ $\mathrm{mmol}), 4 \AA \mathrm{MS}(110 \mathrm{mg}), \mathrm{CH}_{2} \mathrm{Cl}_{2}(1.1 \mathrm{~mL}), 0{ }^{\circ} \mathrm{C}$. ${ }^{\mathrm{b}}$ Yield of isolated product. ${ }^{\mathrm{c}}$ Determined by ${ }^{1} \mathrm{H}$ NMR. ${ }^{\mathrm{d}}$ Determined by HPLC with chiral stationary phases. ${ }^{e}$ No reaction was observed after the indicated time

The optimal conditions established for the $\mathrm{Ca}(\mathrm{OTf})_{2}$ catalyzed reaction (Table 4, entry 8 ) were applied to the reaction of chloromalonates with the same set of $\mathbf{N}$-tosyl imines 2 previously studied in the reaction catalyzed by $\mathrm{La}(\mathrm{OTf})_{3}$. The results are shown in Table 5. In all the cases, products 5 were preferentially obtained as the E-enamines with excellent yields, diastereomeric ratios and enantiomeric excesses, regardless of the electronic nature and substitution pattern of 
the group attached to the double bond and the alkoxy group of the ester moiety. Also, the diastereomeric ratios and enantiomeric excesses were higher than those obtained in the reaction catalyzed by $\mathrm{La}(\mathrm{OTf})_{3}$ as a general trend.

After obtaining these results, we revisited the reaction between diethyl malonate (1) and $\alpha, \beta$-unsaturated $N$-tosyl iminoester 2a. Unfortunately, no advance of the reaction was observed after 5 days at room temperature when it was attempted in the presence of the $\mathrm{Ca}(\mathrm{OTf})_{2}$-pyBOX1-catalyst (Table 5, entry 16), indicating the higher nucleophilicity of diethyl 2-chloromalonate compared with diethyl malonate. Nonetheless, it should be noticed that access to $(E)-3$ compounds would be available through the addition of chloromalonates to imines $\mathbf{2}$ followed by hydrogenolysis of the $\mathrm{C}-\mathrm{Cl}$ bond (see Scheme 3b, below).

\section{Synthetic transformations and determination of the stereochemistry of compounds 5}

We have performed some chemical modifications on compounds $\mathbf{5}$ to show the synthetic potential of the method, as well as to determine their absolute stereochemistry (Scheme 3). Hydrogenolysis of the $\mathrm{C}-\mathrm{Cl}$ bond could be achieved by homogeneous hydrogenation with the $[R h(C O D)] \mathrm{BF}_{4}-d p p p$ complex without isomerization of the double bond nor erosion of the optical purity. ${ }^{\S}$ Upon this treatment, compound $\mathbf{5 a}$, resulting from the La(III)-pyBOX9-catalyzed reaction, was converted into a new enamine 3a (Scheme 3a). This enamine showed identical spectroscopic features but opposite optical rotation sign and chiral HPLC retention times as the product of known stereochemistry $(S, Z)$-3a that results from the addition of diethyl malonate to imine $\mathbf{2 a}$ under $\mathrm{La}(\mathrm{II})$-pyBOX1 catalysis (Table 1, entry 1). ${ }^{15}$ Accordingly, we assigned the $(R, Z)$ stereochemistry to enamine 3a obtained in this way and the the $(S, Z)$ stereochemistry $^{\S \S}$ to the starting 5a (Table 3, entry 1 , Scheme 3a). Hydrolysis of $(R, Z)-3 a$ by treatment with benzylamine gave ketone $(R)-8$ in $92 \%$ yield.

Once we have assigned the $Z$ geometry to the double bond in compound 5a obtained under La(III)-pyBOX9 catalysis we could assign the $E$ geometry to enamine 5a obtained with catalysis by $\mathrm{Ca}(\mathrm{OTf})_{2}$-pyBOx1. To determine its absolute stereochemistry, the hydrogenolysis/hydrolysis sequence was carried out to give again $(R)-8$ (Scheme $3 \mathrm{~b}$ ). This result indicated the $(S, E)$ stereochemistry of the starting enamine $\mathbf{5 a}$ (Table 5, entry 1, Scheme 3b).

The ${ }^{1} \mathrm{H}$ NMR spectrum of compound $(R, Z)$-5a showed a doublet at $\delta 5.07 \mathrm{ppm}(\mathrm{d}, J=9.9 \mathrm{~Hz})$ corresponding to the allylic proton, while for $(S, E)$-5a the signal corresponding to the allylic proton appeared at $\delta 5.62 \mathrm{ppm}(\mathrm{d}, J=10.5 \mathrm{~Hz})$. This trend $\left(\delta_{\mathrm{C}=\mathrm{CCH}}{ }^{E}>\delta_{\mathrm{C}=\mathrm{CCH}}{ }^{2}\right)$ was observed throughout the entire $E / Z$ series of compounds $\mathbf{5}$.

Besides the above transformations, we have achieved the reaction between $(E)$-enamine $(S, E)-5 a$ and hydroxylamine to give a chiral cyclopropane oxime 9 in 90\% yield (Scheme 4). The reaction provided a single diastereomer without any loss of enantiomeric excess with respect to the starting material.

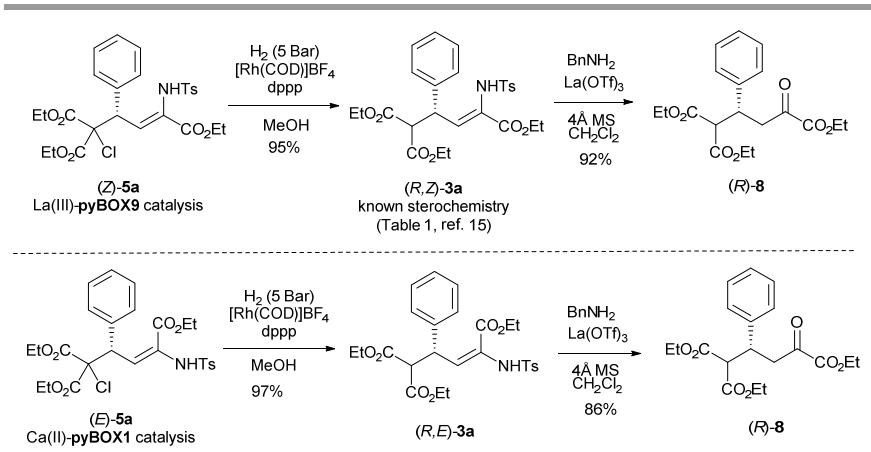

Scheme 3. Synthetic modifications and determination of the absolute stereochemistry of compound 5a obtained under La(III)-pyBOX9 or Ca(II)-pyBOX1 catalysis.

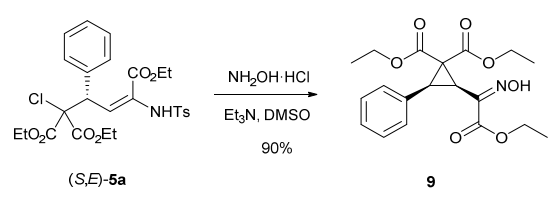

Scheme 4. Synthesis of a cyclopropane derivative from compound $\mathbf{5 a}$.

\section{Computational Investigations}

In order to gain some insight on the reaction mechanism and the origin of the stereoselectivity, some control experiments were performed (Scheme 5). Compounds (Z)-5a and (E)-5a were separately subjected to the optimized Ca(II)-pyBOX1 and La(III)-pyBOX9 conditions, respectively. In both cases, the starting material were recovered unaltered. These results ruled out the possibility of $E / Z$ isomerization occurring after the $\mathrm{C}-\mathrm{C}$ bond formation and indicated that the reaction takes place under kinetic control.

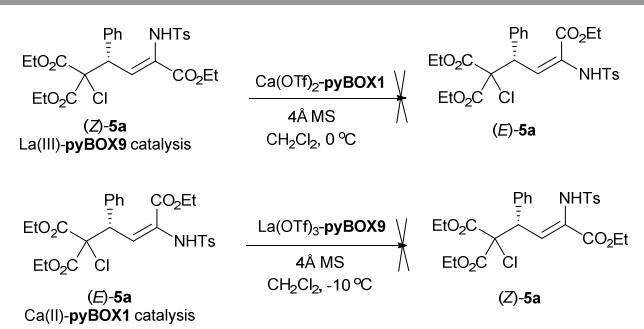

Scheme 5. Control experiments

La(III)-pyBOX complexes $^{16}$ as well as Ca(II)-pyBOX complexes $^{17}$ are well known chiral Lewis acids. In these complexes the metal center coordinates both the imine, enhancing its electrophilic character, and the malonate, favouring its enolization. Such a mode of action, activates both reaction partners and brings them to proximity. According to the stereochemical outcomes observed, the Z-configuration of the double bond of products (Z)-5 in the La(III)-catalyzed reaction indicates the preference of the unsaturated imines $\mathbf{2}$ to adopt an s-cis conformation in the transition state, while in the Cacatalyzed reaction imines $\mathbf{2}$ should adopt the s-trans conformation to give the $E$-enamine. The configuration of the stereogenic center in compounds $\mathbf{5}$ would be the resultant of both: a topological approach of the nucleophile dictated by the stereogenic center of the chiral pyBOX ligand, and the 
conformation of the unsaturated imine dictated by the accommodation of the reacting species in the TS.

To explain these results, we have carried out computational studies comparing the reaction of diethyl chloromalonate (4) and imine 2a under $\mathrm{La}$ (III) or $\mathrm{Ca}$ (II) catalysis. In order to prioritize the role of the metal on the stereochemistry, the study has been carried out using in both cases pyBOX1 as the

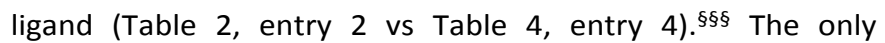
approach considered was replacing the ethyl esters by the corresponding methyl esters. According to previously studied reactions catalyzed by pyBOX complexes, it is expected that after the formation of the catalytic species CAT, the reagents complex to the metal atom, through a barrierless process, leading to the starting encounter complex EC (Scheme 6). The number of triflate ligands is that required to keep EC neutral. We have calculated the corresponding cationic complexes and, in all cases, resulted less stable. Similarly, solvation with additional water molecules or an extra equivalent of substrate or product can be ruled out on the basis of the corresponding complexes are less stable. Accordingly, we assume a monotriflate complex for calcium and a bistriflate complex for lanthanum. Complex EC evolves through a transition state TS (the rate-limiting step) to produce the final complex FC which releases the product PR regenerating the catalytic species CAT and closing the catalytic cycle. Four final complexes FC with configurations $(Z, R),(Z, S),(E, R)$ and $(E, S)$ leading to the corresponding products PR can be obtained. Although several encounter complexes can be formed, in agreement with the Curtin-Hammett principle, ${ }^{18}$ they are in equilibrium and the selectivity of the reaction will depend from the relative barriers of all the possible transition states TS. Accordingly, we studied computationally the process corresponding to the rate-limiting step, i.e. the transformation of EC into $\mathrm{FC}$ through TS. Although the $(E)$-imine is more stable than the (Z)-imine (by $5.1 \mathrm{kcal} / \mathrm{mol}$ ), there is a rapid equilibrium between both isomers of sulfinyl imines ${ }^{19}$ so, in agreement to CurtinHammett's principle, ${ }^{18}$ the participation of the (Z)-isomer cannot be discarded a priori. In consequence, to locate possible transition structures TS we initially worked with $N$-Ms imines ( $\mathrm{R}=\mathrm{Me})$ and defined approaches for $(E)$ - and $(Z)$-imines adopting $\mathrm{s}$-cis and s-trans conformations between the imino and double bonds, by $R e$ and Si faces. We considered three staggered orientations for each approach, thus being a total of twenty-four approaches leading to the four different isomers that can be obtained (see Figure S1 in SI). Both reactions catalyzed by $\mathrm{La}(\mathrm{TfO})_{3}$ and $\mathrm{Ca}(\mathrm{OTf})_{2}$ were calculated. For this reduced model, the Boltzmann distributions of the 24 transition structures calculated for each catalyst indicated that, in both cases, the preferred isomer should be $(Z, S)$-FC ( $97 \%$ for Ca-catalyzed and $99 \%$ for La-catalyzed). Clearly, this result does not reproduce the experimental observations but the real model bears at the imine nitrogen an aromatic group that might promote decisive London interactions, as observed in other asymmetric catalytic reactions. ${ }^{20}$ Accordingly, the best approach leading to each isomer was selected and grown up to the real model, i.e. $N$-Ts imines (Scheme 5, $\mathrm{R}=4-\mathrm{MeC}_{6} \mathrm{H}_{4}$ ).

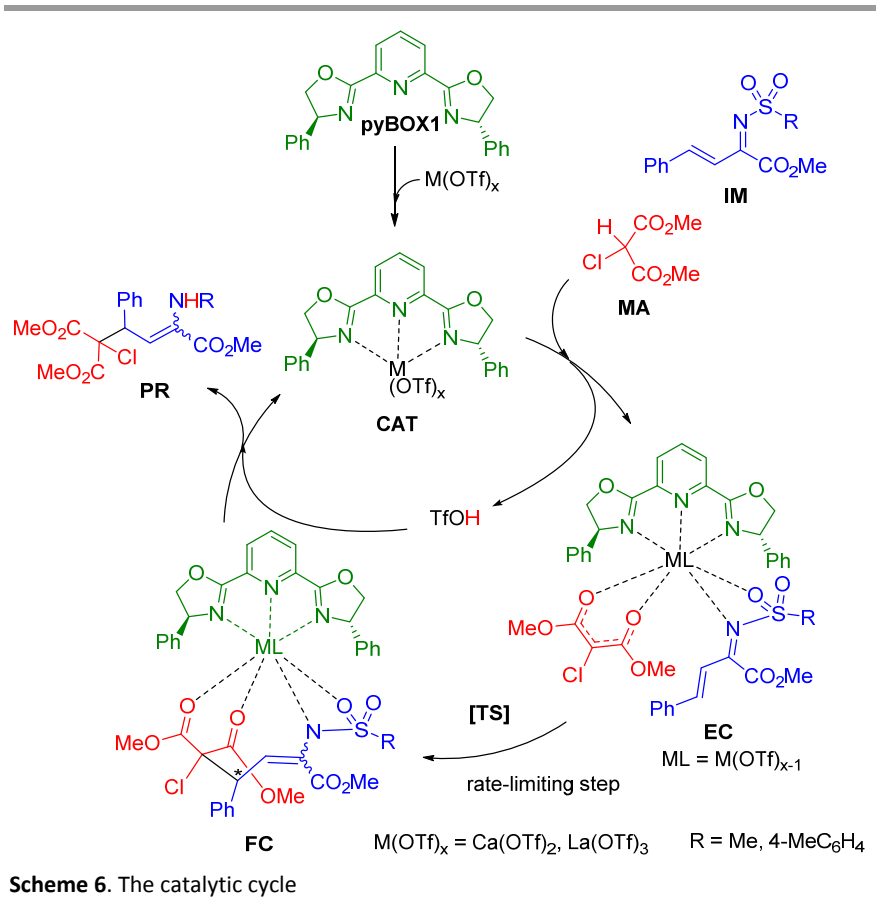

The four transition structures leading to the corresponding isomers for each reaction were located at b3lyp-3dbj/def2svp level of theory (Figure 1). Calculation of energies at b3lyp$\mathrm{d} 3 \mathrm{bj} / \mathrm{def} 2 \mathrm{tzvp} / \mathrm{pcm}=\mathrm{DCM}$ level indicated that the preferred approach (92\%) for the La-catalyzed reaction was that leading to $(Z, R)$-FC (precursor of $(Z, R)$-PR) while for the Ca-catalyzed reaction the preferred approach (99\%) was that leading to $(E, S)$-FC (precursor of $(E, S)-\mathbf{P R})$ as observed experimentally. Calculations also predict correctly the observed high, but not complete, selectivity observed for the La-catalyzed reaction (Table 3, entry 1 ) as well as the essentially complete selectivity observed for the Ca-catalyzed reaction (Table 5, entry 1 ). These results are in perfect agreement with the experimental observations and point out the importance of using real models without any restriction, particularly when aromatic residues are involved. ${ }^{20}$

The analysis of the optimized geometries of the transition structures revealed interesting features that justify the observed differences in energies. For both La- and Cacatalyzed reactions the preferred transition state showed stabilizing London interactions between the $\mathrm{N}$-Ts group and one aromatic group of the catalyst. These London interactions were corroborated through a topological analysis of noncovalent interactions $(\mathrm{NCl}) .{ }^{21}$ As illustrated in Figure 2, the preferred transition structure for the La-catalyzed reaction showed a green surface characteristic of $\pi, \pi$-interactions and that preferred for the Ca-catalyzed reaction showed a surface typical of $\mathrm{CH}-\pi$ interactions. The different coordination features of La and $\mathrm{Ca}$ due to their valence and number of triflate ligands accounts for the different geometries of the complexes induced by the above-mentioned London interactions, resulting in different selectivity preferences. 


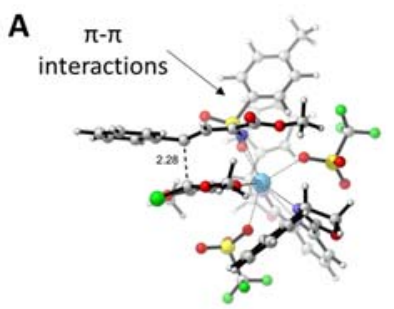

$(Z, R e)-T S$

$(0.0,92 \%)$

B

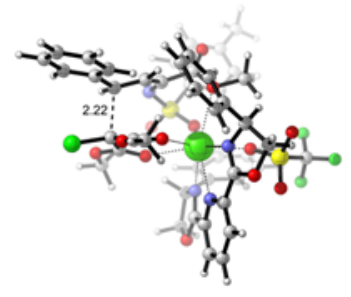

(Z,Re)-TS

(6.6, 0\%)<smiles>COC(=O)C(=CC(c1ccccc1)C(Cl)(C(C)=O)C(C)=O)C(C)=O</smiles>

$(Z, R)-\mathbf{P R}$

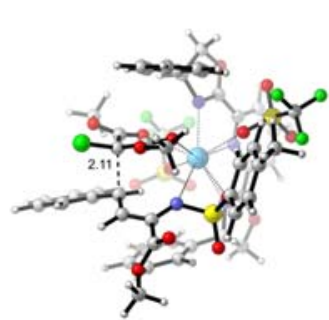

(Z,Si)-TS

(4.6, 0\%)

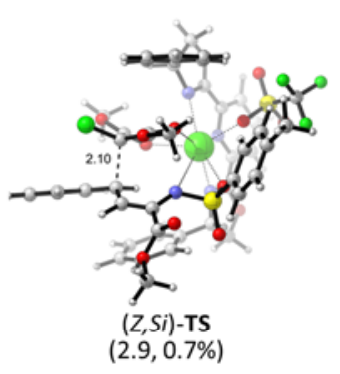

$\checkmark$

$\mathrm{MeO}_{2}{ }_{\mathrm{MeO}_{2} \mathrm{C}}^{\mathrm{Ph}} \mathrm{CO}_{2}^{\mathrm{NHT}} \mathrm{Me}$

$(Z, S)$-PR

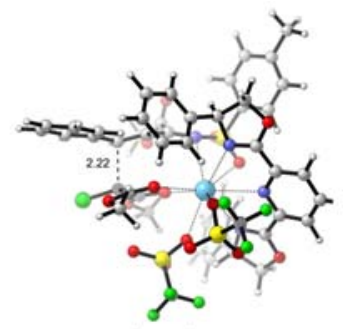

(E,Re)-TS

$(1.5,8 \%)$

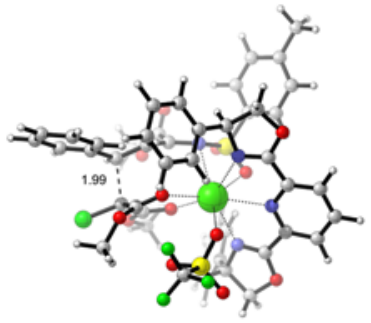

(E,Re)-TS

(13.8, 0\%)

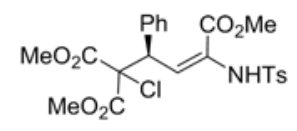

$(E, R)-\mathbf{P R}$

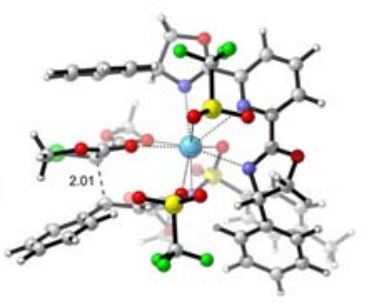

(E,Si)-TS

(19.5, 0\%)

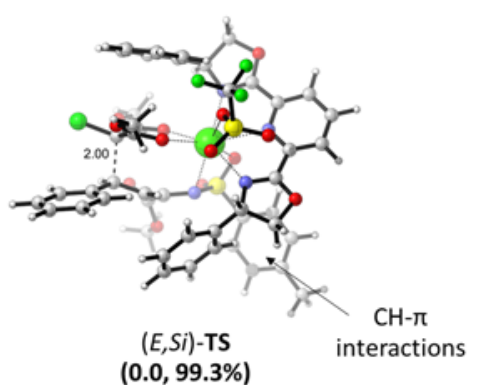

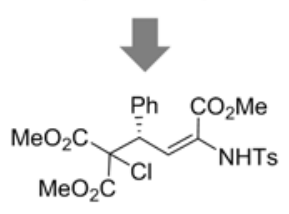

( $E, S)$-PR

Figure 1. Transition structures for $\mathrm{N}$-Ts imines. A: La-catalyzed. B: Ca-catalyzed. Relative energies are given in kcal/mol. Percent values correspond to Boltzmann distribution.

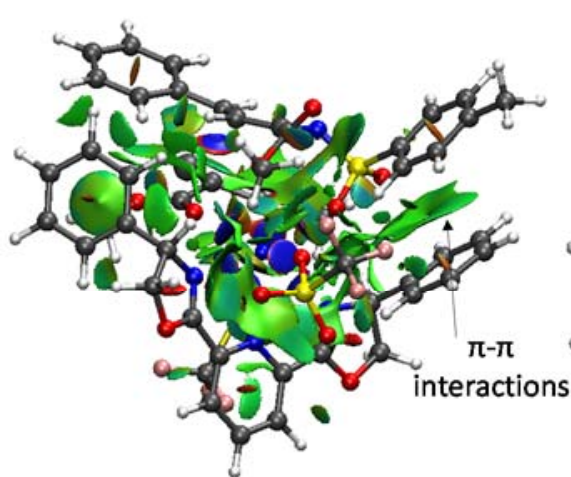

$(Z, R e)-\mathrm{TS}$

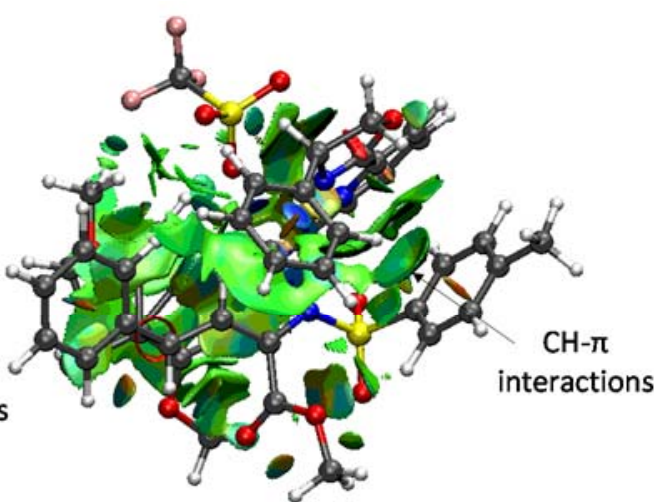

(E,Si)-TS

Figure 2. $\mathrm{NCl}$ calculations for (Z,Re)-TS (La-catalyzed reaction) and (E,Si)-TS (Ca-catalyzed reaction

We also calculated the energy barrier of the reaction (for energy profiles, see Figure S2 in SI) and it was found to be of $5.0 \mathrm{kcal} / \mathrm{mol}$ for the La-catalyzed reaction and $4.1 \mathrm{kcal} / \mathrm{mol}$ for the Ca-catalyzed reaction, in agreement with processes that take place smoothly at $0 \circ \mathrm{C}$. Moreover, calculations also predict a faster Ca-catalyzed reaction with respect to the La-catalyzed reaction. This result is also in an excellent agreement with the experimental observations $(40 \mathrm{~h}$ for La-catalyzed reaction,
Table 3, entry 1; $25 \mathrm{~h}$ for Ca-catalyzed reaction, Table 5, entry 1).

\section{Conclusions}

We have developed procedures for the asymmetric diastereodivergent conjugate addition of 2-chloromalonate ester derivatives to $N$-tosylimines derived from $\beta, \gamma$ unsaturated $\alpha$-keto esters to give chiral $\alpha, \beta$ - 
dehydroaminoesters. Diastereoselectivity is simply achieved by changing the metal ion in the pyBOX complex catalyst. The addition of diethyl 2-chloromalonate catalyzed by La(OTf) $3^{-}$ pyBOX-complexes led to the corresponding dehydroaminoesters with the $Z$-configuration at the double bond with high enantiomeric excesses. On the other hand, pyBOX-Ca(OTf $)_{2}$ complexes catalyzed the addition of diethyl 2chloromalonate favoring the formation of the dehydroaminoesters with the $E$-configuration with excellent enantioselectivity. The computational study with the real model, i.e. considering the presence of an aromatic residue at the imine nitrogen correctly predicts the observed differences in both reactivity and selectivity between La-catalyzed and Cacatalyzed reactions. Crucial London interactions, revealed by topological $\mathrm{NCl}$ calculations, between that aromatic residue and those of the catalyst are decisive in the change of selectivity depending on the used metal. The observed differences in the interactions between the aromatic residues in Ca-catalyzed and La-catalyzed reactions are conditioned bythe different coordination modes which induce different preferred transition structures. According to these findings it is possible predict similar results for catalysts containing metals with the same valence and coordination sphere that La or Ca. Moreover, by combining the computational results of $\mathrm{N}-\mathrm{Ms}$ and $\mathrm{N}$-Ts imines is possible to predict a complete lack of selectivity of the former due to absence of stabilizing aromatic London interactions. Given the crucial role of London interactions between aromatic residues it might be also plausible that catalysts with alkyl groups at the place of phenyl groups could produce a reduced selectivity, even though other types of stabilizing London interactions between alkyl groups that may lead to different selectivities cannot be discarded. ${ }^{22}$

\section{Conflicts of interest}

There are no conflicts to declare.

\section{Acknowledgements}

Financial support from the Agencia Estatal de Investigación (AEI, Spanish Government) and Fondo Europeo de Desarrollo Regional (FEDER, European Union) (CTQ2017-84900-P and CTQ2016-76155-R) is acknowledged. Access to NMR and MS facilities from the Servei Central de Suport a la Investigació Experimental (SCSIE)-UV is also acknowledged. The authors thankfully acknowledge the resources from the supercomputers "Memento" and "Cierzo", technical expertise and assistance provided by BIFI-ZCAM (Universidad de Zaragoza, Spain).

\section{Notes and references}

\# Initial experiments were conducted using diethyl 2bromomalonate instead of diethyl 2-chloromalonate. However, variable amounts of debrominated compound $\mathbf{3 a}$ were obtained besides the expected Michael addition product 5'a (structure as $\mathbf{5 a}$ but $\mathrm{Br}$ instead of $\mathrm{Cl}$ ). Product $\mathbf{3 a}$ probably arises via bromide exchange between diethyl bromomalonate and compound 5'a. See SI for this preliminary study with dialkyl bromomalonates. $\S$ Hydrogenolysis with $\mathrm{H}_{2}$ on $\mathrm{Pd} / \mathrm{C}$ or by treatment with $\mathrm{PhSH}$ led to considerable isomerization of the double bond.

$\S \S$ Please, note that the shift of configuration notation from compound $\mathbf{5 a}$ to compound $\mathbf{3 a}$ in Scheme 3 is due to the change of priority numbering of the substituents on the stereogenic center when applying the Cahn-Ingold-Prelog rules.

$\S \S \S$ This approach is based on the similar performance of the La(III)-pyBOX1 and La(III)-pyBOX9 (Table 2, entry 2 vs entry 10). It should be noted, however, that pyBOX1 and pyBOx9 have opposite configurations and they lead to different enantiomers.

1 a) A. S. Gross and M. Eichelbaum, Adv. Drug Res., 1996, 28, 1-64; b) K. Jozwiak, W. J. Lough and I. W. Wainer, Drug Stereochemistry: Analytical Methods and Pharmacology, 3rd ed., CRC Press: 2012; c) Foye's Principles of Medicinal Chemistry, 7th Ed., (Eds.: T. L. Lemke, D. A. Williams, V. F. Roche, S. W. Zito), Lippincott Williams \& Wilkins, Wolters Kluwer: Baltimore, 2013; d) Chiral Drugs: Chemistry and Biological Action, (Eds.: G.-Q. Li, Q.-D. You, J.-F. Cheng), Wiley: Hobooken, 2011.

2 Comprehensive Chirality (Eds.: E. M. Carreira, H. Yamamoto), Elsevier Science, Amsterdam, 2012; Vols. 1-9.

3 For first time postulation and conceptualization of stereodivergence see: a) M. Luparia, M. T. Oliveira, D. Audisio, F. Frébault, R. Goddard and N. Maulide, Angew. Chem. Int. Ed., 2011, 50, 12631; b) D. Audisio, M. Luparia, M. T. Oliveira, D. Klütt and N. Maulide, Angew. Chem. Int. Ed., 2012, 51, 7314.

4 For reviews, see: a) M. T. Oliveira, M. Luparia, D. Audisio, N. Maulide, Angew. Chem, Int. Ed., 2013, 52, 13149; b) M. Bihani and J. C.-G. Zhao, Adv. Synth. Catal., 2017, 359, 534; c) L. Lin and X. Feng, Chem. Eur. J., 2017, 23, 6464; d) G. Zhan, W. Du and Y.-C. Chen, Chem. Soc. Rev., 2017, 46, 1675; e) S. Krautwald and E. M. Carreira, J. Am. Chem. Soc., 2017, 139, 5627; f) I. P. Beletskaya, C. Najera and M. Yus, Chem. Rev., 2018, 118, 5080.

5 a) S. Krautwald, D. Sarlah, M. A. Schafroth and E. M. Carreira, Science 2013, 340, 1065; b) M. Mechler and R. Peters, Angew. Chem. Int. Ed., 2015, 54, 10303; c) S. B. J. Kan, H. Maruyama, M. Akakura, T. Kano, K. Maruoka, Angew. Chem. Int. Ed. 2017, 56, 9487; d) L. Zhang, H. Yuan, W. Lin, Y. Cheng, P. Li and W. Li, Org. Lett., 2018, 20, 4970; e) X. Huo, J. Zhang, J. Fu, R. He and W. Zhang, J. Am. Chem. Soc., 2018, 140, $2080 ;$ f) D. Kaldre, I. Klose and N. Maulide, Science, 2018, 361, 664 .

6 J. Esquivias, R. Gómez Arrayás and J. C. Carretero, J. Org. Chem., 2005, 70, 7451.

7 a) F. Palacios and J. Vicario, Org. Lett., 2006, 8, 5405. b) F. Palacios and J. Vicario, Synthesis, 2007, 3923.

8 a) A. Lee and H. Kim, J. Am. Chem. Soc., 2015, 137, 11250. b) A. Lee and H. Kim, J. Org. Chem., 2016, 81, 3520.

9 Y. Huang, R. J. Chew, S. A. Pullarkat, Y. Li and P. H. Leung, J. Org. Chem., 2012, 77, 6849.

10 B.-C. Da, Q.-J. Liang, Y.-C. Luo, T. Ahmad and Y.-H. Xu, ACS Catal., 2018, 8, 6239.

11 a) M. Espinosa, G. Blay, L. Cardona, J. R. Pedro, Chem. Eur. J. 2013, 19, 14861. b) M. Espinosa, G. Blay, L. Cardona, J. R. Pedro, Chem. Eur. J. 2013, 19, 17632 (correction).

12 M. Espinosa, A. García-Ortiz, G. Blay, L. Cardona, M. C. Muñoz and J. R. Pedro, RSC Adv., 2016, 6, 15655.

13 a) U. Kazmaier, Synthesis and Chemistry of $\alpha, \beta$ Didehydroamino acids In Amino Acids, Peptides and Proteins in Organic Chemistry (Ed. A. E. Andrew), Wiley-VCH: Weinheim, Germany, 2009 Vol 2, pp 3. b) M. A. Blaskovich, In Handbook on Syntheses of Amino Acids. General Route to Amino Acids, A CS and Oxford University Press: New York, 
2010; pp. 225. c) J Jiang, Z. Ma and S. L. Castle, Tetrahedron, 2015, 71, 5431.

14 C. Dugave and L. Demange, Chem. Rev., 2003, 103, 2475.

15 These preliminary results have been published: M. Espinosa, G. Blay, L. Cardona, I. Fernandez, M. C. Muñoz and J. R. Pedro, J. Coord. Chem. 2018, 71, 864.

16 a) G. Desimoni, G. Faita, M. Guala, A. Laurenti, M. Mella, Chem. Eur. J., 2005, 11, 3816; b) G. Desimoni, G. Faita, F. Piccinini, M. Toscanini, Eur. J. Org. Chem., 2006, 5228.

17 a) T. Poisson, Y. Yamashita and S. Kobayashi, J. Am. Chem Soc., 2010, 132, 7890; b) K. Lippur, S. Kaabel, I. Järving, K. Rissanen and T. Kanger, J. Org. Chem., 2015, 80, 6336

18 J. I. Seeman Chem, Rev., 1983, 83, 83.

19 M. Hennum, H. Fliegl, L.-L. Gundersen and O. Eisenstein, J. Org. Chem., 2014, 79, 2514.

20 For recent examples see: a) D. Roca-López, U. Uria, E. Reyes, L. Carrillo, K. A. Jørgensen, J. L. Vicario and P. Merino, Chem. Eur. J., 2016, 22, 884. b) A. Ortega, R. Manzano, U. Uria, L. Carrillo, E. Reyes, T. Tejero, P. Merino and J. L. Vicario, Angew. Chem. Int. Ed., 2018, 57, 8225.

21 E. R. Johnson, S. Keinan, P. Mori-Sanchez, J. ContrerasGarcia, A. J. Cohen and W. Yang, J. Am. Chem. Soc., 2010, 132, 6498.

22 For the importance of London interactions in organic reactivity see: J. P. Wagner and P. R. Schreiner, Angew. Chem. Int. Ed., 2015, 54, 12274. 